\title{
The mouse map gets a lot more signposts
}

That researchers' staple, the laboratory mouse, has undergone the ultimate dissection: two competing teams have completed the most thorough maps yet of its genetic variation.

The catalogue of 8.27 million genetic differences provides a unique insight into the evolutionary origins of the mouse, and researchers also anticipate that it will speed up the discovery of disease-causing mutations in mice and ultimately in humans.

Although the two groups disagree over the evolutionary history of the lab mouse (Mus musculus), they both assert that the maps will give researchers fast access to an unparallelled cache of genetic information on hundreds of lab strains. "It's a whole new era of mouse genetics," says Gary Churchill, a mouse geneticist at Jackson Laboratory in Bar Harbor, Maine, and an author on one of the studies (H. Yang, T. A. Bell, G. A. Churchill \& P.-M. de Villena Nature Genet. doi:10.1038/ng2087; 2007).

The researchers traced the lineage of small chunks of the mouse genome in 11 common lab strains back to four wild subspecies. Because of the genetic similarity between the 450-odd inbred classical lab strains, a relatively small number of single-nucleotide polymorphisms (SNPs), which are one-base-pair differences between two strains, can now be

used to deduce the sequences of more than 8 million SNPs using the new map. If one segment of the genome can be attributed to a single ancestor, then all mouse strains that share that segment should have the same SNPs. As few as 50,000 SNPs spread across the genome per strain are needed to deduce the rest of the 8 million.

"You don't have to go and resequence [their genomes]," says Richard Mott, a bioinformatician at the Wellcome Trust Centre for Human Genetics in Oxford, UK, who was not involved in the studies. "That's tremendous."

Mus musculus is the most important model organism for human disease and the standardbearer in cancer and immunology research, as $99 \%$ of mouse genes have a human counterpart. In the early 1900s, Abbie Lathrop, a former schoolteacher in Massachusetts, started breeding mice obtained from fanciers in Europe and Asia. These animals spawned the first lab, which were made genetically pure through dozens of generations of sibling mating. "It was really, truly just a handful of mice," says Kelly Frazer, a geneticist who led the second mapping effort while at the biotechnology company Perlegen Sciences in Mountain View, California (K. A. Frazer et al. Nature, doi:10.1038/nature06067; 2007).

Subtle differences between strains - A/J

\section{Mice unlimited}

Imagine a laboratory that is home to a thousand strains of mice, maintained by a dedicated staff and visited by scientists seeking access to the most diverse collection of lab mice in the world. This is the vision of geneticist Gary Churchill at Jackson Laboratory in Bar Harbor, Maine. "It's a new model, and I don't think biologists have embraced it yet," he says. Yet a loosely knit team of hundreds of researchers all over the world called the Complex Trait Consortium is already at work providing the mouse strains that would fill such a facility.
Launched in 2005, the consortium's Collaborative Cross project seeks to quadruple the genetic diversity represented by the 450 or so classical mouse lab strains. More mice with relevant phenotypes will help geneticists winkle out the genes and mutations that underlie complex traits and diseases.

Currently, huge swathes of the genome differ little between lab strains - genetic blind spots that complicate attempts to associate genes with disease. Reshuffling the mouse gene deck will eliminate such blind spots, says consortium member David Threadgill, a geneticist at the University of North Carolina in Chapel Hill. Hosted by Oak Ridge National Laboratory in Tennessee, the breeding project is just getting under way with eight strains of mice being crossed in hundreds of combinations.

Each combination will be interbred for at least 25 generations to ensure new strains are pure-breeding. Already, 400 lines have been bred for 10 generations and those strains should be ready within three years, says Churchill.

E.C.

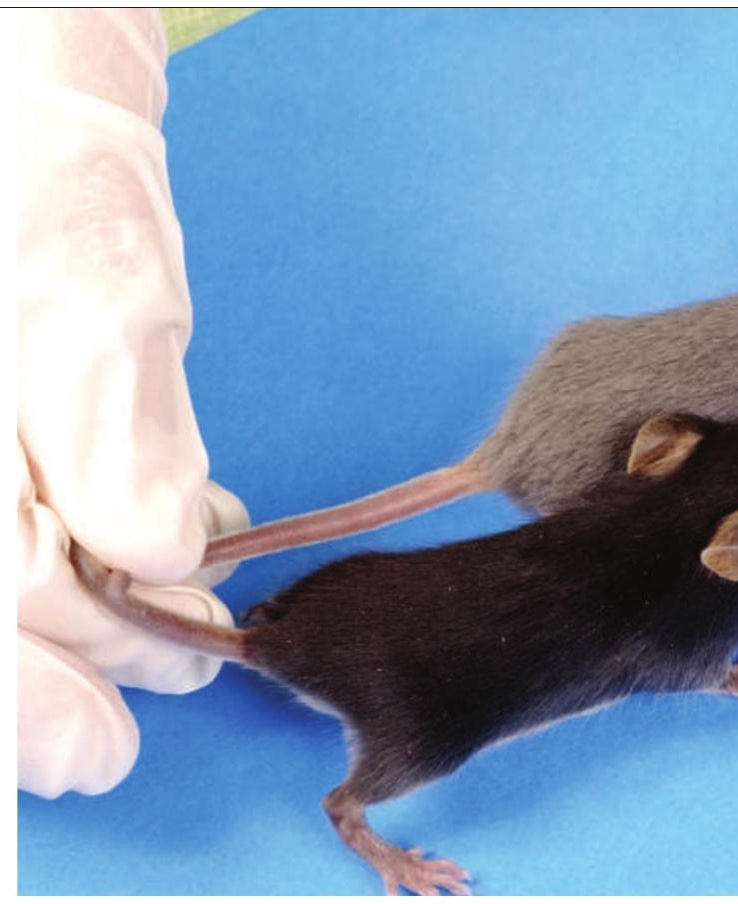

Signs of diversity: coat colour was the first way in which different mouse strains were recognized.

mice are prone to cancer and $\mathrm{BALB} / \mathrm{cJ}$ mice are susceptible to the bacterium Listeria, for example - can be traced to SNPs, of which fewer than 45 million are thought to exist in lab and wild strains together.

\section{Difference matters}

The first mouse genome to be sequenced was that of C57BL/6J, in 2002. The US National Institute of Environmental Health Sciences in Triangle Park, North Carolina, teamed up with Perlegen to roughly sequence 10 more strains, plus four subspecies of wild mice collected from all over the world. The sequences were completed in 2006 and made freely available.

To tease out more detail and to make the information applicable to other mouse strains, Frazer's team made a genomic map of each sequenced strain, and established the ancestral subspecies that gave rise to around 40,000 segments of the genome. Overall, says Frazer, a subspecies from Europe called domesticus contributes most (68\%) of the lab mouse genome, but this varies from chromosome to chromosome and strain to strain.

Frazer's team didn't know that Churchill's team was doing the same thing. "It would have been nice if the two groups had talked with one another," she says, "but they didn't let us know they were doing it."

Using a slightly different method, Churchill and his colleagues at the University of North Carolina at Chapel Hill also conclude that domesticus provides the lion's share of diversity in lab mice, more 


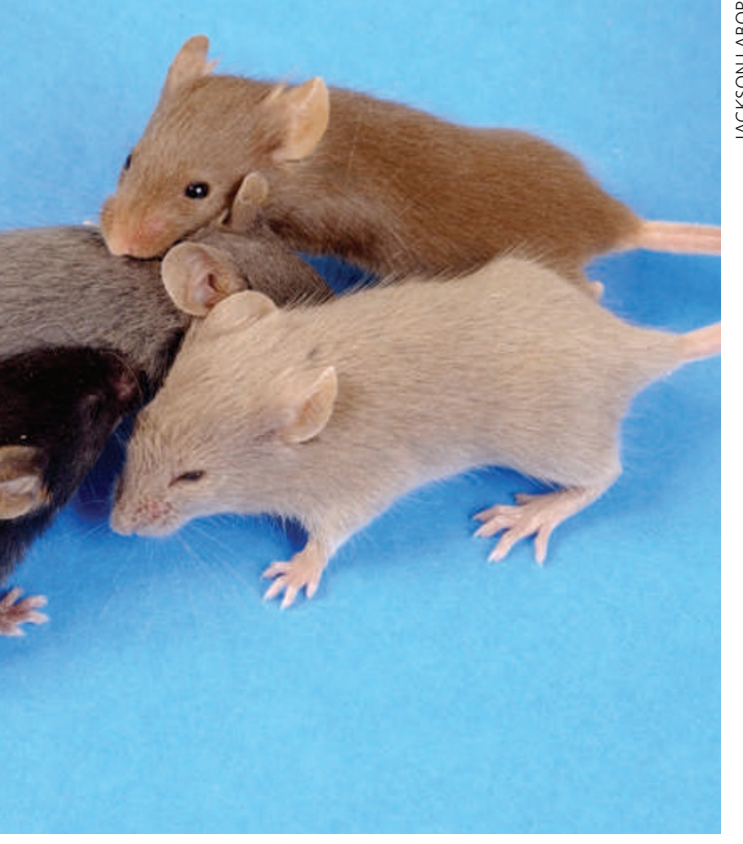

than $90 \%$. He says that the mouse genome is far more complex than he had thought. "This has been an unfolding story," he says. "We saw patterns that were so confusing." What has emerged is only a partial sketch, he says. Sequencing the entire genomes of more laboratory and wild strains will paint a fuller picture and settle the differences between the two maps. "It's going to be resolved," Churchill says.

Although the teams present two evolutionary histories for the lab mouse, "the similarities are more important than the differences," Mott says. And the ability to deduce polymorphisms in other strains doesn't depend on an unambiguous history.

Researchers will be eager to make use of the data, say both teams. Mark Daly at the Broad Institute in Cambridge, Massachusetts, and a coauthor with Frazer, has already applied the map to 100 strains of mice that had been genotyped for 150,000 SNPs, and will soon be able to assign millions more SNPs to these mice.

The projects could also spur the use of less common lab strains by providing better genetic maps, says Elizabeth Fisher, a geneticist at University College London. "There's an enormous amount of diversity out there that we're not capitalizing on," she says. A collaboration of hundreds of researchers called the Complex Trait Consortium plans to breed 1,000 new mouse strains (see 'Mice unlimited'). And now those strains will be easily genotyped. "It's going to allow us to make better mouse lines for the future, with levels of diversity that are more like human diversity," Churchill says.

Ewen Callaway

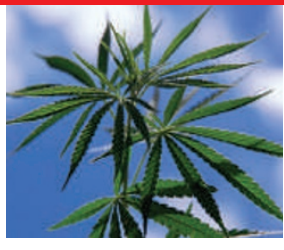

MEDICAL OPINION COMES FULL CIRCLE ON CANNABIS DANGERS

Frequent use more than doubles psychosis risk.

www.nature.com/news

\section{Q\&A: Jürgen Graeser}

On 29 August, Jürgen Graeser of the Alfred Wegener Institute for Polar and Marine Research in Potsdam, Germany, will embark on an eight-month Russian-led voyage on a d rifting ice floe to the North Pole. The German will join 35 Russian colleagues from the Arctic and Antarctic Research Institute in St Petersburg, Russia, to collect a wealth of atmospheric and sea-ice data in one of the most remote and inhospitable regions of the planet. Quirin Schiermeier spoke to the first Westerner invited to spend time on a Russian drifting station.

Why is this expedition special?

There'll be no ship, no aircraft, no fixed route, nothing. We will never know what the next day will bring. For me, this is the ultimate challenge. Work in Arctic stations has, of late, become quite comfortable. I've read many books about what 'real' expeditions were like, but I never thought it would be possible to participate in such an adventure.

\section{Where will you be at the winter solstice?}

I'll be drifting in the Arctic Ocean, somewhere near the North Pole, on an ice floe some 2 kilometres across and 3 metres thick. A suitable floe is being sought now. The Russians will build a makeshift research base on it made of prefabricated wooden cabins.

\section{What will your daily routine be?}

I'll be in charge of a small 'aerological' station, doing a range of atmospheric and meteorological measurements. I'll also use radiosondes and a tethered balloon to make a profile of the ozone and aerosol concentrations in the lowest layer of the atmosphere. Such high-resolution measurements have never been taken before at such high latitudes. At the end of each day, I'll transmit the most basic data to Germany. Satellite communication beyond $80^{\circ} \mathrm{N}$ is extremely slow, so this will take some time. Other than that, the days will be punctuated by the meals we'll eat together.

\section{Russia is claiming parts of the Arctic. Is there a political background to the project?}

The expedition is not equipped to search for geological evidence that could back up such claims. During preparatory meetings, the plans for exactly what the Russian team will do have had a low profile, but I doubt that any ill will is intended. The Russians have been using drifting stations for more than 50 years, and this is the first time a foreigner has been invited, which signals improved scientific openness towards the West.

There's an agreement that all data will be made openly available as well.

\section{What can go wrong?}

You need to be constantly aware of polar bears. All team members have been trained to shoot. Also, the floe might become unstable or break. The worst case would be if the floe were to sink. This happened in 2004, and the whole team had to be evacuated by helicopter. Alcohol is also a bit of a concern: each member of the team is officially permitted one can of beer and one bottle of spirits per week. I would have preferred a bit more beer and less spirits. Drink can have disastrous consequences there.

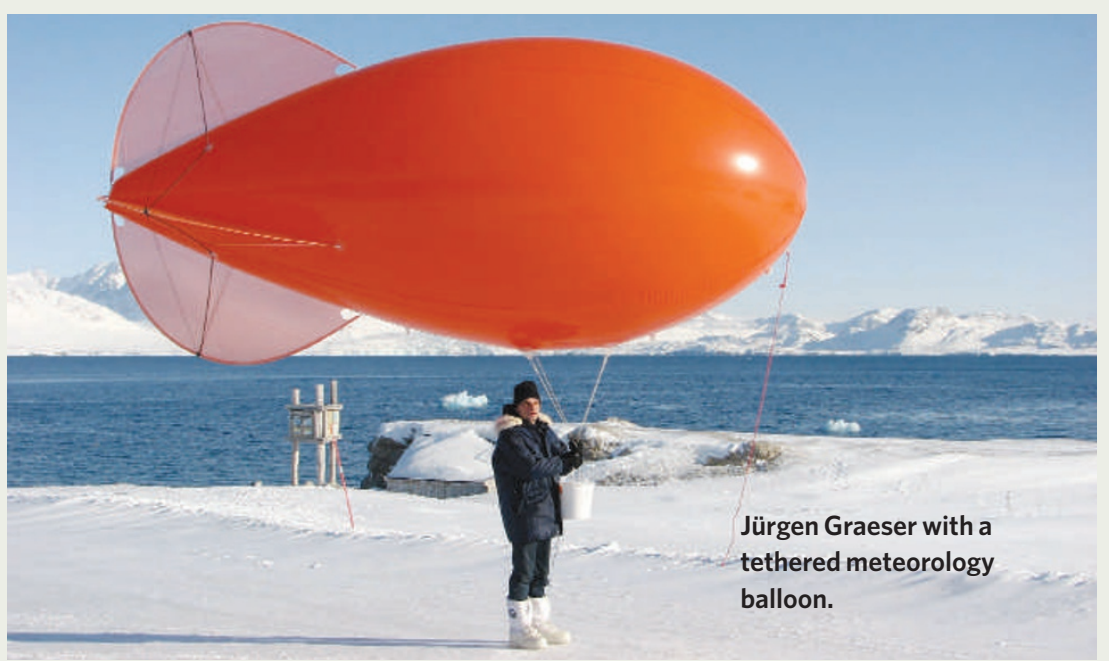

